
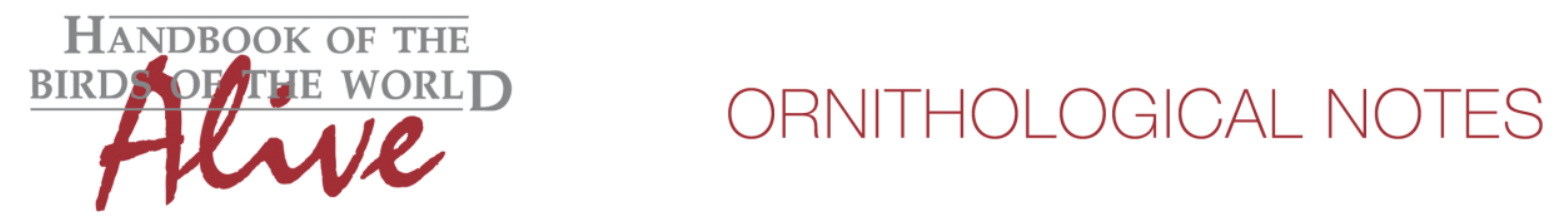

\title{
Notes on the vocalizations of Spotted Bush-warbler (Bradypterus thoracicus)
}

Peter Boesman

In the following we briefly analyze and compare voice of the three races of Spotted Bushwarbler (Bradypterus thoracicus). We also try to quantify the extent of any vocal differences using the criteria proposed by Tobias et al. (2010), as a support for taxonomic review.

We have made use of sound recordings available on-line from Xeno Canto (XC) and Macaulay Library (ML).

Voice has already been extensively studied in Alström et al. (2008), and measurements of basic sound parameters are provided:

Table 6. Characteristics of songs

\begin{tabular}{|c|c|c|c|}
\hline & thoracicus/pryevalskii & kashmirensis & davidi/suschkini \\
\hline 'Strophe' length (ms) & $558-749(626 \pm 32 ; 60)$ & $908-1444(1170 \pm 116 ; 53)$ & $359-497(423 \pm 33 ; 70)^{*}$ \\
\hline Buzz length (ms)† & $76-118(101 \pm 9.3 ; 50)$ & $105-220(157 \pm 40 ; 58)$ & $359-497(423 \pm 33 ; 70)^{*}$ \\
\hline Frequency span buzz $(\mathrm{Hz}) \dagger$ & $1470-25112005 \pm 248 ; 50$ & $1344-2823(2136 \pm 331 ; 58)$ & $1933-2782(2395 \pm 195 ; 70)$ \\
\hline Mean frequency buzz $(\mathrm{Hz}) \dagger$ & $5412-5956(5648 \pm 135 ; 50)$ & $5847-6698(6287 \pm 274 ; 58)$ & $5208-6179(5673 \pm 269 ; 70)$ \\
\hline
\end{tabular}

Values in parentheses: (mean $\pm \mathrm{SD} ; N$ ).

*In our terminology, the buzzes of davidi/suschkini are synonymous with 'strophes', but these notes are presumably not homologous with the 'strophes' of thoracicus/przevalskii and kashmirensis, but instead with the buzzes in the strophes of these taxa.

†Both buzzes in each strophe in kashmirensis; length of first buzz 105-143 ms (mean 118 \pm 0.009 ), second buzz $164-220 \mathrm{~ms}$ (mean $195 \pm 0.01$ ).

Based on these data we can calculate effect sizes (ES) for thoracicus/przevalskii vs.

kashmirensis:

strophe length

ES 6.39

pause length

ES 2.18

buzz length

ES 1.93

freq. span

ES 0.45

mean freq.

ES 2.96

(Application of the term 'strophe' could be questioned, as it possibly leads to comparing not homologous parts of the song (1 phrase vs. 2 grouped phrases). In any case, a score can only be given for either strophe length or pause duration.)

Strict application of Tobias criteria based on the measurements in the paper would lead to score 3 for strophe length and score 2 for mean freq., resulting in a total score of 5 .

Qualitatively, vocal difference lies mainly in the fact that thoracicus/przevalski has a repeated strophe which contains a single buzz, while kashmirensis has a repeated strophe which contains twice a buzz (Alström et al. 2008). 


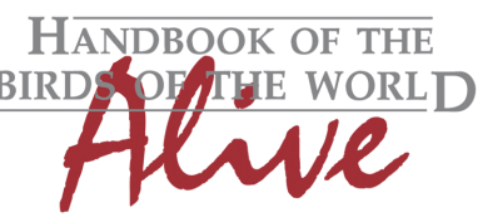

\section{ORNITHOLOGICAL NOTES}

Some examples of song of thoracicus/przevalski:

Typical song:

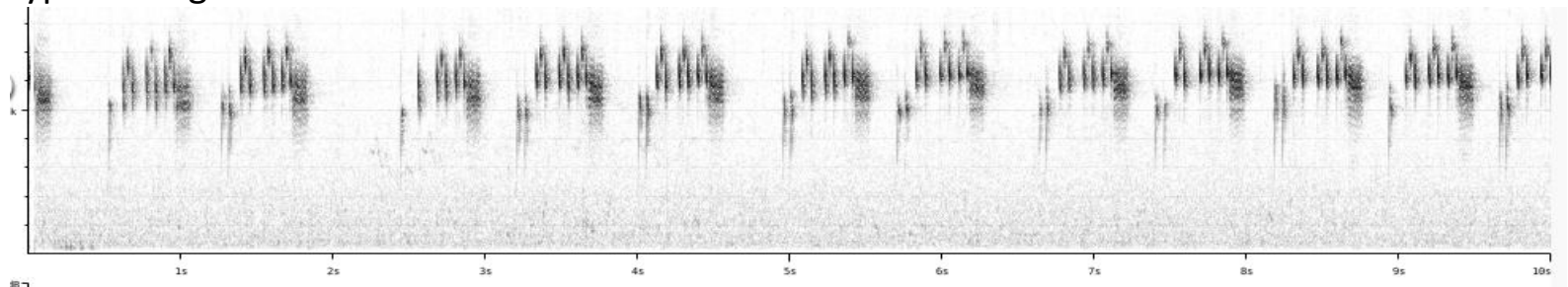

less typical variations:
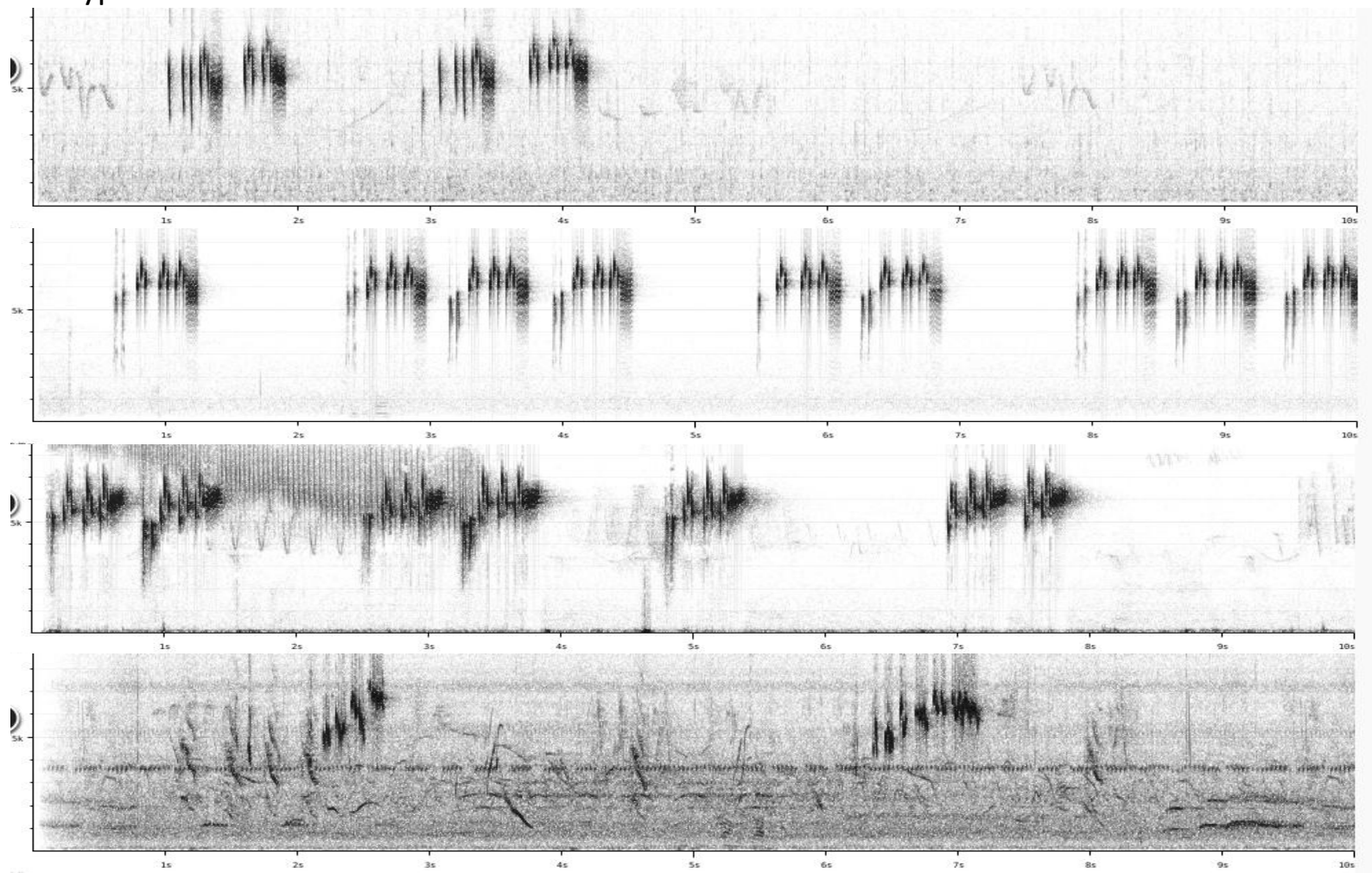

From these examples it would seem that the situation is somewhat less clear-cut, with strophes not necessarily being identical.

We have only found one recording of kashmirensis:

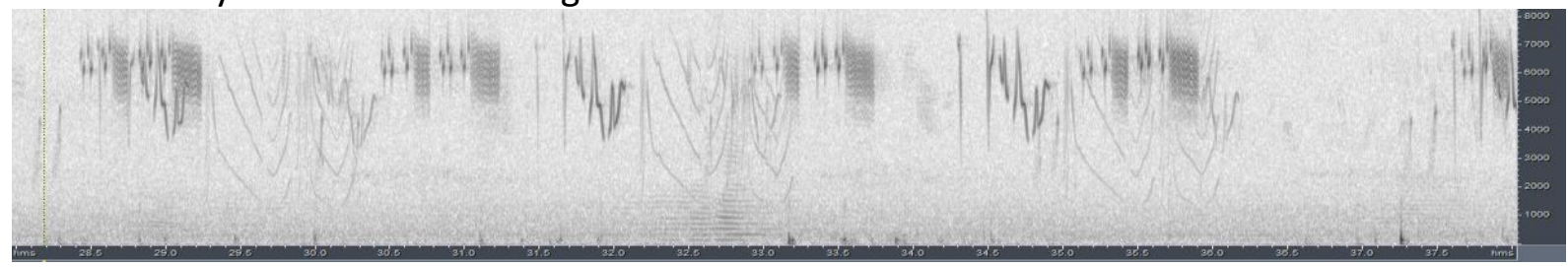

This recording indeed nicely shows the 'doubled strophes' (with the first and second not identical, the second one having a longer buzz etc., which is different from the occasional 'double strophes' in thoracicus/przevalski ) 


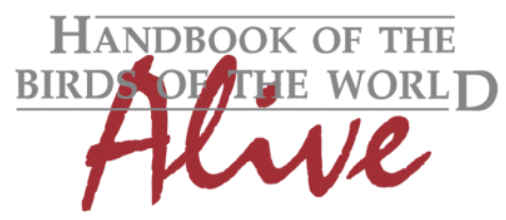

\section{ORNITHOLOGICAL NOTES}

It would seem that the aforementioned study suffered somewhat from small sample size of sound recordings, as reflected in Table 1 of the paper. Nevertheless, it is clear that the songs of both groups are different.

An alternative, more pragmatic way of scoring ( 3 for single vs. double buzz in smallest repeated unit, 1-2 for lower frequency of the buzz etc.), would lead to a similar total score of 4-5.

This can be illustrated by the following detail of typical song phrases for both groups (arrows indicating average buzz frequency):

\section{kashmirensis}

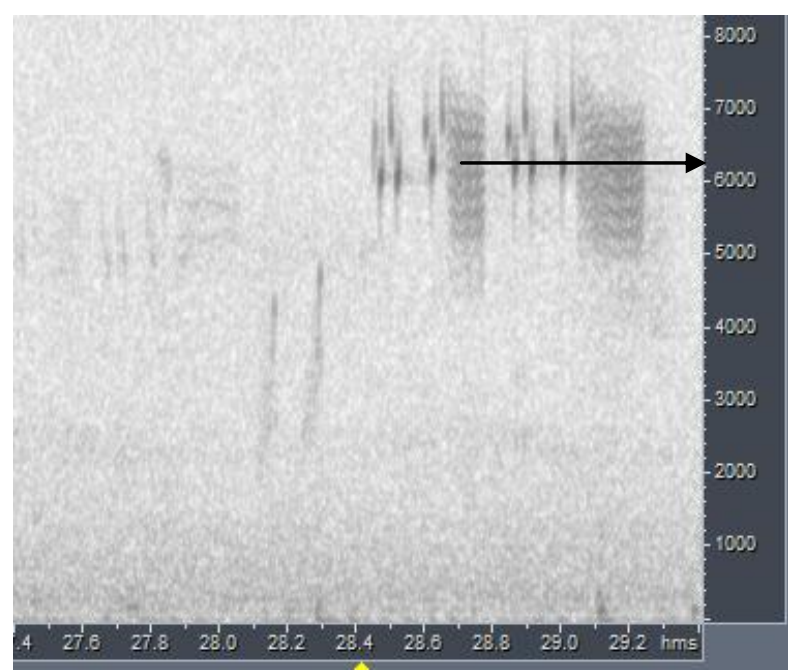

thoracicus/przevalski

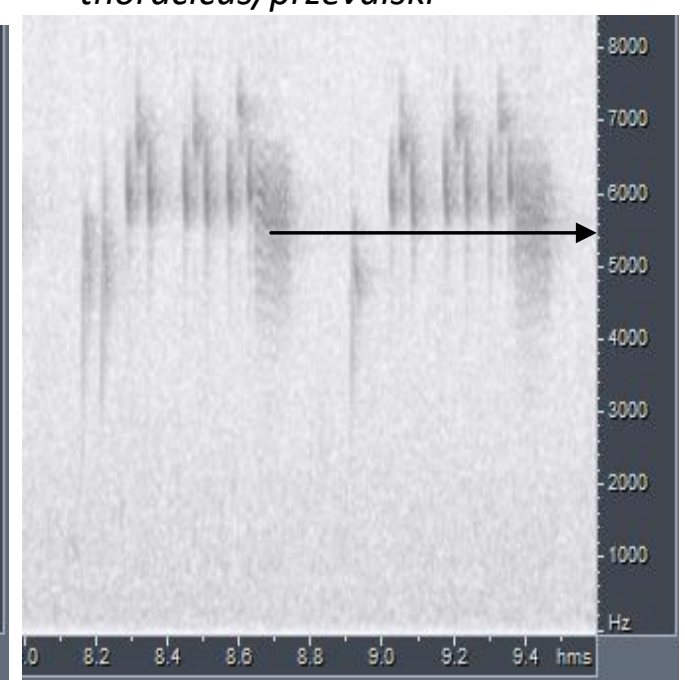

One final word of caution: all L.t. thoracicus recordings are from China. For some reason, none of the thoracicus recordings from India (Nepal, Assam) are of the 'typical type':

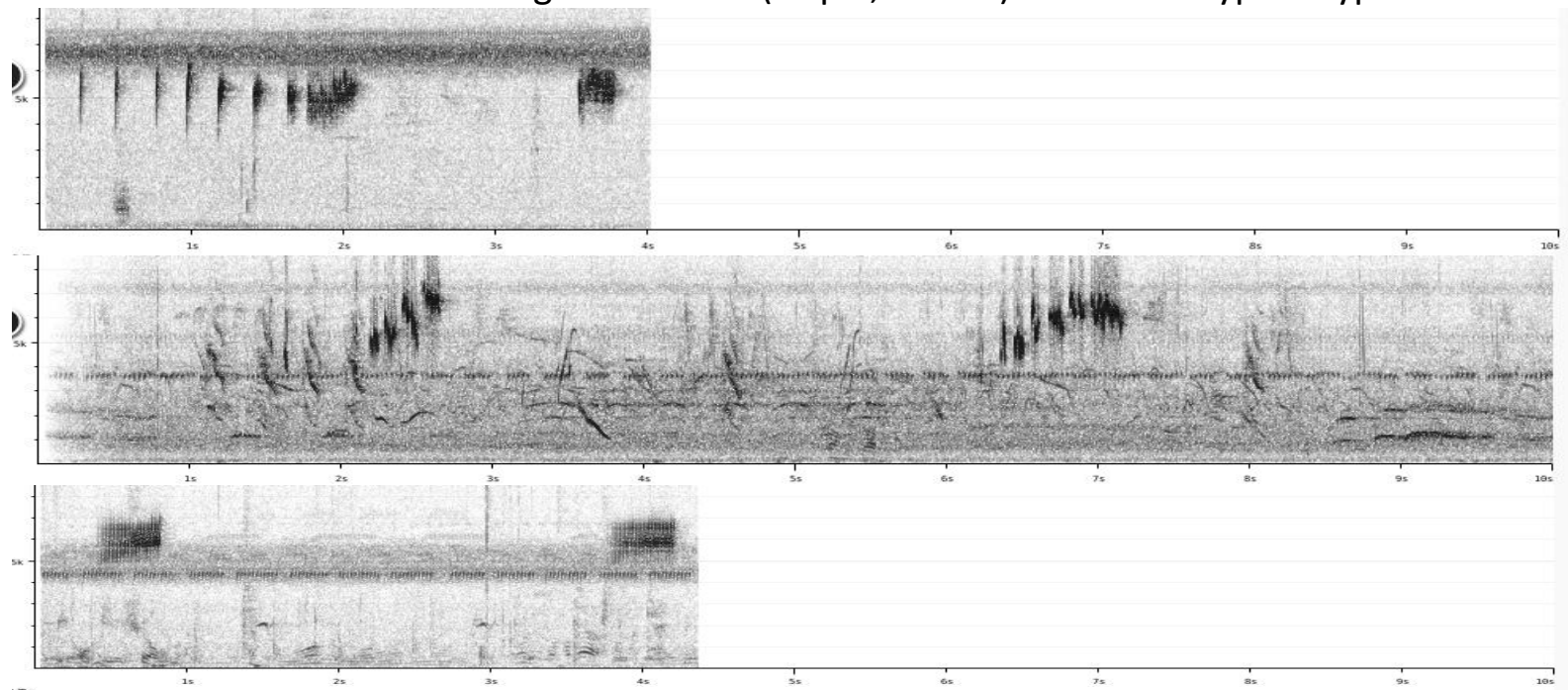

Something seems to be overlooked here. Either, these are vocalizations of an overwintering different Bush Warbler, there is a cryptic taxon here different from Chinese thoracicus, or simply these are not yet the May-June spring songs... This is clearly food for further study. 

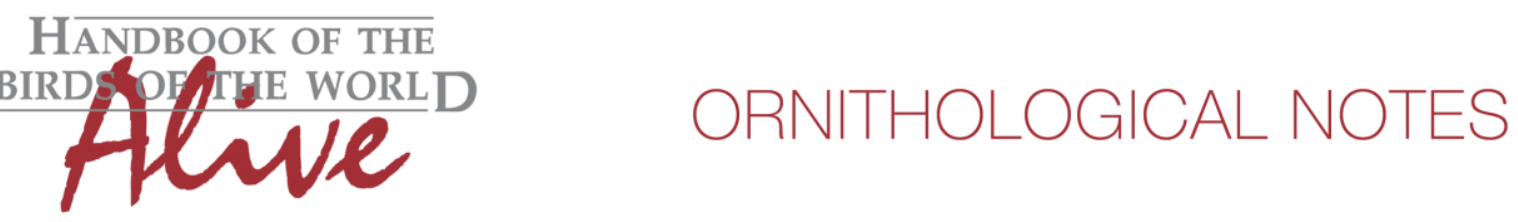

This note was finalized on 15th February 2016, using sound recordings available on-line at that moment. We would like to thank in particular the sound recordists who placed their recordings for this species on XC: Nick Athanas, Oscar Campbell, Tomas Carlberg, David Farrow, Frank Lambert, Mike Nelson, Craig Robson, Ding Li Yong and Sahas Barve Aditya Malgaonkar.

\section{References}

Alström, P., Rasmussen, P.C., Olsson, U. \& Sundberg, P. (2008). Species delimitation based on multiple criteria: the Spotted Bush Warbler Bradypterus thoracicus complex (Aves:

Megaluridae). Zool. J. Linn. Soc. 154: 291-307.

Tobias, J.A., Seddon, N., Spottiswoode, C.N., Pilgrim, J.D., Fishpool, L.D.C. \& Collar, N.J. (2010). Quantitative criteria for species delimitation. Ibis 152(4): 724-746.

\section{Recommended citation}

Boesman, P. (2016). Notes on the vocalizations of Spotted Bush-warbler (Bradypterus thoracicus). HBW Alive Ornithological Note 236. In: Handbook of the Birds of the World Alive. Lynx Edicions, Barcelona. (retrieved from http://www.hbw.com/node/932199 on 29 September 2016). 